\title{
Baroreflex sensitivity and cardiovascular mortality in patients with mild to moderate heart failure
}

Karl Josef Osterziel, Dankward Hänlein, Roland Willenbrock, Christina Eichhorn, Friedrich Luft, Rainer Dietz

\begin{abstract}
Objective-To assess the influence of both sympathetic (plasma noradrenaline concentrations) and parasympathetic (baroreflex activation) tone on survival in patients with congestive heart failure.

Design-Invasive study with determination of parasympathetic activity and follow up for at least $4 \cdot 5$ years.

Subjects-35 patients with sinus rhythm

centration also contributed to survival. An additional contribution of vagal tone to survival could not be shown when sympathetic tone was considered simultaneously. This may be due to the inverse relation of sympathetic and parasympathetic tone and to the insensitivity of the multiple regression method to identify additional risk factors in small numbers of patients.
\end{abstract} and mild to moderate heart failure (New York Heart Association grades II-III) (mean age 53 (SD 3)).

Results-20 patients whose hearts survived were compared with 15 patients whose hearts did not (12 died and three received transplants). The two groups differed significantly in terms of mean arterial blood pressure (98 (3) $v 90$ (3) $\mathrm{mm} \mathrm{Hg}$ ), heart rate $(82$ (2) v 93 (4) beats/min), and mean pulmonary artery pressure (24 (3) $v 35$ (2) $\mathrm{mm} \mathrm{Hg}$ ) (all $\mathrm{P}<$ $0 \cdot 05$ ), while cardiac index, stroke volume index, and right atrial pressures were not different. The survivors had significantly lower plasma renin activities (3.6 (0.8) $v$ 9.0 (3.6) angiotensin $\mathrm{I} / \mathrm{ml} / \mathrm{h} ; P<0.05)$ and tended to have lower noradrenaline values than non-survivors (170 (23) $v 286$ (74) $\mathrm{pg} / \mathrm{ml}$ ) at baseline. Baroreflex sensitivity was significantly lower in nonsurvivors than in survivors $(1.3(0.2) v 2.3$ $(0.3) \mathrm{ms} / \mathrm{mm} / \mathrm{Hg}) ; P<0.02)$. As the time of cardiac transplantation is dependent on complex logistical factors the three patients who received a transplant were excluded from the analysis of survival time. The risk of death in relation to baroreflex sensitivity at the median sensitivity of $1.48 \mathrm{~ms} / \mathrm{mm} \mathrm{Hg}$ was calculated. Survival was significantly different $(P<$ $0 \cdot 04)$ between the resulting two groups; three of the 16 subjects with high baroreflex sensitivity died compared with nine of the 16 with a baroreflex sensitivity $<1.48 \mathrm{~ms} / \mathrm{mm} \mathrm{Hg}$. When systemic blood pressure, pulmonary artery pressure, stroke volume index, plasma noradrenaline concentrations, and baroreflex sensitivity were entered into a Cox proportional hazards regression, only systolic blood pressure and plasma noradrenaline values predicted survival $(P<0.001)$.

Conclusions-Low vagal tone is correlated with a poor prognosis in patients with heart failure. Sympathetic tone measured as plasma noradrenaline con-
(Br Heart f 1995;73:517-522)

Keywords: renin-angiotensin-system; parasympathetic nervous system; prognosis; heart failure

Ejection fraction and plasma noradrenaline concentration are important variables predicting survival in patients with congestive heart failure. ${ }^{1-3}$ Cohn and colleagues showed that noradrenaline concentration as a measure of sympathetic tone was inversely correlated with survival. ${ }^{4}{ }^{5}$ Patients with congestive heart failure have not only increased sympathetic activation but also decreased vagal (parasympathetic) tone. ${ }^{67}$ Baroreceptor activation reflects parasympathetic tone in that an increase in baroreceptor sensitivity indicates a greater decrease in heart rate when the baroreceptor is activated. Conversely, a decrease in baroreflex sensitivity is associated with a lesser decrease in heart rate with baroreceptor activation. ${ }^{8}$ Recent data showing that sudden death increased when baroreflex sensitivity was decreased in patients with myocardial infarction who did not have congestive heart failure underscore an important role for parasympathetic tone. ${ }^{910} \mathrm{We}$ examined parasympathetic tone in patients with symptomatic heart failure. Our hypothesis was that parasympathetic tone itself would be an indicator of survival.

\section{Patients and methods}

We identified 35 patients with mild to moderate congestive heart failure (New York Heart Association grades II-III), and sinus rhythm. Heart failure was caused by idiopathic dilated cardiomyopathy in 28 patients and coronary artery disease in seven patients as confirmed by cardiac catheterisation. All patients were limited by symptoms and signs of heart failure and not by angina. Concomitant treatment with $\beta$ blockers was not allowed. The low proportion of patients with coronary artery disease and sinus rhythm was due to the fact that 
many patients were limited by angina and often treated with $\beta$ blockers at the time of evaluation and had to be excluded. At entry into the study the patients were investigated haemodynamically and their baroreflex sensitivity was determined. Twenty eight patients were taking diuretics and 26 patients were receiving maintenance treatment with digitoxin. Four patients received quinidine, one in combination with verapamil, and one patient received mexiletine. All patients were given an angiotensin converting enzyme inhibitor on discharge from the hospital after having been studied.

We used a modification of the technique described by Ludbrock et al, to measure baroreflex sensitivity. ${ }^{11}$ Briefly, a tightly fitting chamber was placed around the neck of the patients, which permitted rapid $(<0.1 \mathrm{~s})$ suction to $40 \mathrm{~mm} \mathrm{Hg}$ negative pressure. The time course of the reflex response allowed the increase in parasympathetic nerve activity to be determined. The negative transmural pressure at the carotid sinus receptors stimulated the baroreceptor reflex by simulating an increase in systemic blood pressure. The reflex response was determined as the decrease in heart rate expressed per cardiac cycle length. Neck suction was applied in random order twice at $0,-10,-20,-30$, and $-40 \mathrm{~mm} \mathrm{Hg}$ for $30 \mathrm{~s}$. We calculated one regression line and its slope from these values of neck suction and the according increases in cardiac cycle length for each patient. For the calculation of maximal baroreflex sensitivity, the maximal cycle length was subtracted from the average of five cycle lengths before the suction was applied. ${ }^{12}$ In addition, baroreflex sensitivity was determined from the increase in cycle length from the two cardiac cycles immediately before and after neck suction, according to the method of Ebert et al. ${ }^{13}$ The two results were termed the maximal and the immediate baroreflex sensitivity respectively. Although not tested in this study, the repro-

Table 1 Comparison of patients still living after 56 months (survivors) with those who died $(n=12)$ or received transplants $(n=3)$ (non-survivors). Values are means $(S D)$ unless stated otherwise

\begin{tabular}{|c|c|c|c|}
\hline & $\begin{array}{l}\text { Survivors } \\
(n=20)\end{array}$ & $\begin{array}{l}\text { Non-survivors } \\
(n=15)\end{array}$ & $\begin{array}{l}P \\
\text { value }\end{array}$ \\
\hline \multicolumn{4}{|l|}{ No of patients with: } \\
\hline Cardiomyopathy & 15 & 13 & NS \\
\hline Coronary artery disease & 5 & 2 & NS \\
\hline Age (years) & $51(2)$ & $5 \overline{5}(3)$ & NS \\
\hline Height $(\mathrm{cm})$ & $173(2)$ & $174(2)$ & NS \\
\hline Weight (kg) & $80(3)$ & $71(4)$ & 0.04 \\
\hline Mean blood pressure $(\mathrm{mm} \mathrm{Hg})$ & $98(3)$ & $90(3)$ & 0.04 \\
\hline Heart rate (beats $/ \mathrm{min}$ ) & $82(2)$ & $93(4)$ & 0.04 \\
\hline Cardiac index $\left(1 / \mathrm{min} / \mathrm{m}^{2}\right)$ & $3 \cdot 2(0 \cdot 1)$ & $2.9(0 \cdot 2)$ & NS \\
\hline Stroke volume index $\left(\mathrm{ml} / \mathrm{m}^{2}\right)$ & $39(2)$ & $33(2)$ & 0.057 \\
\hline Mean pulmonary artery pressure $(\mathrm{mm} \mathrm{Hg})$ & $24(3)$ & $35(2)$ & 0.003 \\
\hline Mean right atrial pressure $(\mathrm{mm} \mathrm{Hg})$ & $7(1)$ & 9 (1) & NS \\
\hline Systemic vascular resistance (dynes $\mathrm{s} / \mathrm{cm}^{5}$ ) & $1268(77)$ & $1255(68)$ & NS \\
\hline Plasma adrenaline $(\mathrm{pg} / \mathrm{ml})$ & $63(9)$ & $66(19)$ & NS \\
\hline Plasma noradrenaline $(\mathrm{pg} / \mathrm{ml})$ & $170(23)$ & $286(74)$ & NS \\
\hline Plasma renin activity (ng angioten $\sin \mathrm{I} / \mathrm{ml} / \mathrm{h}$ ) & $3.6(0.8)$ & $9.0(3.6)$ & 0.03 \\
\hline Serum sodium $(\mathrm{mmol} / \mathrm{l})$ & $140(1)$ & $137(1)$ & 0.05 \\
\hline Serum potassium $(\mathrm{mmol} / \mathrm{l})$ & $3.9(0 \cdot 1)$ & $3.8(0 \cdot 1)$ & NS \\
\hline Serum creatinine $(\mathrm{mg} / 100 \mathrm{ml})$ & $1 \cdot 1(0 \cdot 1)$ & $1.4(0.1)$ & NS \\
\hline \multicolumn{4}{|l|}{ Baroreflex sensitivity $(\mathrm{ms} / \mathrm{mm} \mathrm{Hg})$ : } \\
\hline Maximal & $2 \cdot 3(0 \cdot 3)$ & $1 \cdot 3(0 \cdot 2)$ & 0.02 \\
\hline Immediate & $2.1(0.4)$ & $1 \cdot 1(0 \cdot 3)$ & 0.02 \\
\hline Survival time (months) & $>56$ & $26(4)$ & \\
\hline
\end{tabular}

ducibility of baroreflex determination is good: there was no change in the slope of baroreflex sensitivity after administration of placebo in another study. ${ }^{13}$

Haemodynamic variables were measured by a Swan-Ganz catheter placed in the pulmonary artery. Cardiac output was measured by thermodilution. The mean of three determinations with a variation of $<10 \%$ was taken as the cardiac output. Plasma renin activity and adrenaline and noradrenaline concentrations were measured by radioimmunoassay and radioenzymatic assay respectively. ${ }^{14} 15$ Serum sodium and creatinine concentrations were measured by an automated method. ${ }^{16}$

\section{STATISTICAL ANALYSIS}

Groups were compared by the non-parametric Wilcoxon-Mann-Whitney test. The survival distribution function was determined by the Kaplan-Meier method. Differences between groups were examined by the Mantel-Cox, Tarone-Ware, Breslow, and Peto-Prentice tests. Multivariate regression analysis was performed using the Cox proportional hazards model. Only covariates which contributed significantly to an improvement in the prediction of survival were entered into the model. Fiducial limits are expressed as means (SD). A probability of $\mathrm{P}<0.05$ was accepted as significant.

\section{Results}

The patients were followed up for a minimum of 56 months. By this time 12 patients had died and three had undergone cardiac transplantation because of refractory heart failure. These 15 patients (non-survivors) were compared with the 20 patients whose hearts had survived the 56 months. As outlined in table 1 , the groups did not differ in terms of aetiology of heart failure, age, and height but were marginally different in body weight. At the time of baroreflex determination survivors had a slightly greater systolic, diastolic, and mean systemic pressure; lower heart rate; and lower pulmonary artery pressure than the non-survivors (figure 1). Cardiac index, right atrial pressure, and systemic vascular resistance, however, did not differ. Serum sodium concentration was lower and the serum creatinine concentration slightly higher in non-survivors than in survivors. Plasma renin activity was higher in non-survivors than in survivors; however, adrenaline and noradrenaline values were not different. As shown in figure 2 , both the maximal and the immediate baroreflex sensitivity were significantly lower in non-survivors than in survivors.

The patients who died were classified according to whether their death fitted the clinical classification of cardiac death. ${ }^{17} \mathrm{We}$ next compared all the above variables in the six patients within the non-survivors who died suddenly and the nine patients who died of progressive congestive heart failure or received a transplanted heart. None of the variables examined were significantly different between those who died suddenly and those 

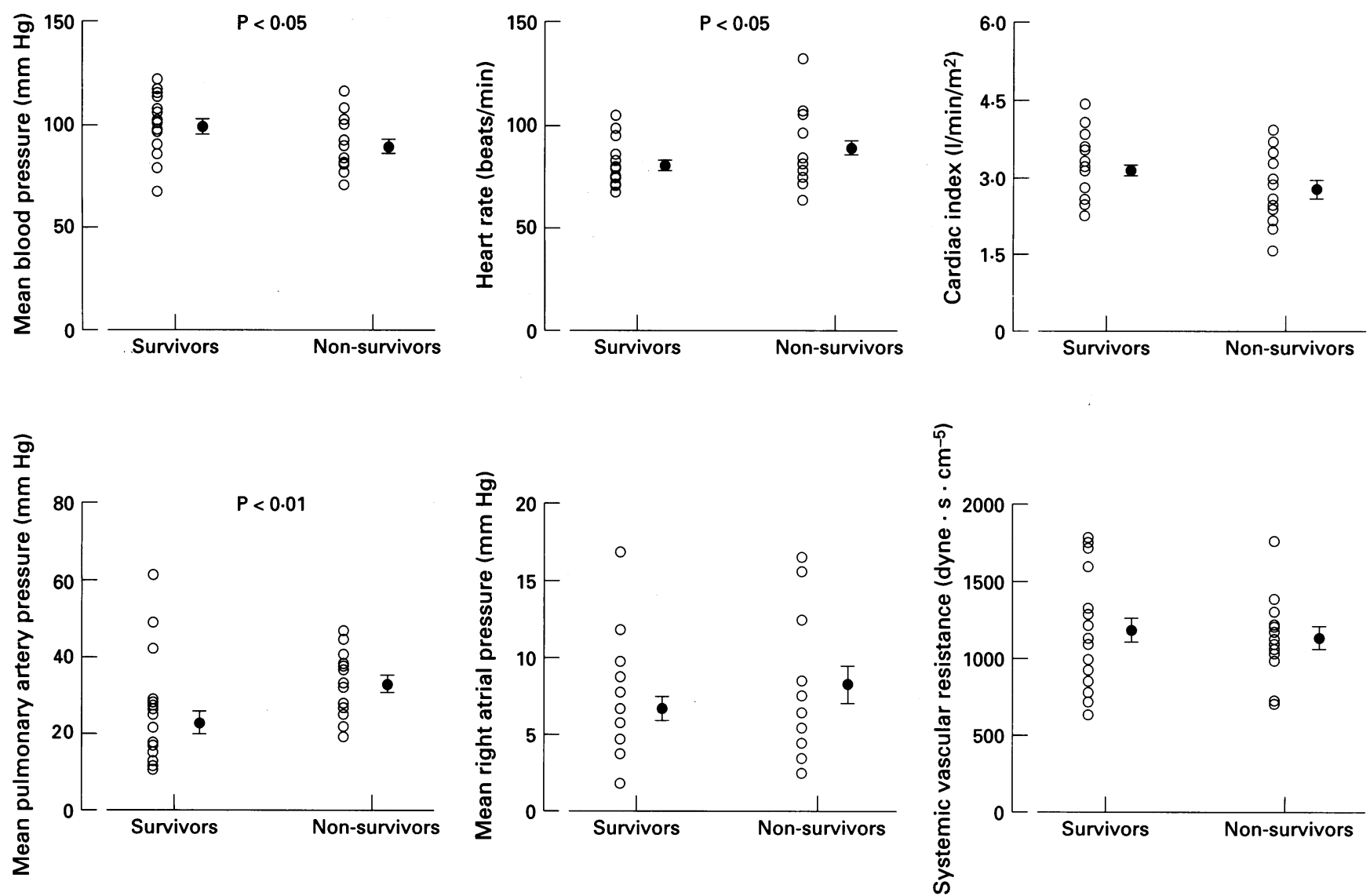

Figure 1 Comparison of haemodynamic variables at baseline between survivors and non-survivors (those who died or received heart transplants for refractory heart failure).

who died of congestive heart failure or received transplants (table 2 ).

Because the timing of cardiac transplantation is dependent on complex logistical factors

Figure 2 Maximal and immediate baroreflex sensitivity in survivors and non-survivors.

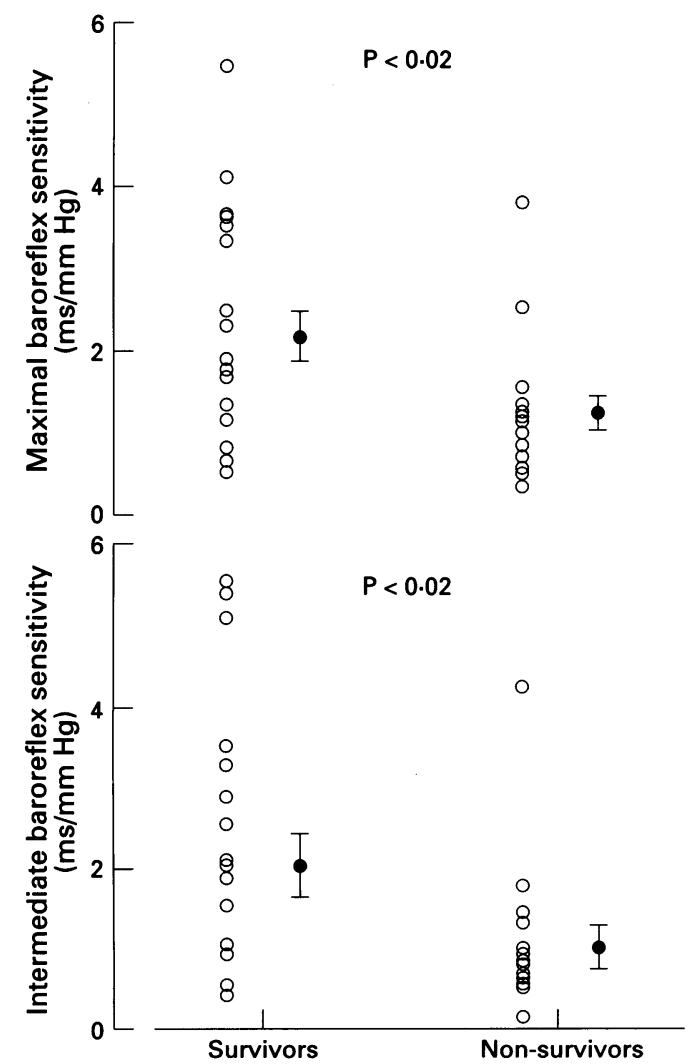

the three patients who developed terminal heart failure and received a transplant were excluded from the following analysis on survival. To calculate the risk of mortality in relation to the baroreflex sensitivity we arbitrarily used the median in the remaining 32 patients as a cut off point (median of the maximal baroreflex sensitivity $=1.48 \mathrm{~ms} / \mathrm{mm} \mathrm{Hg}$ ). After 56 months (figure 3), the mortality

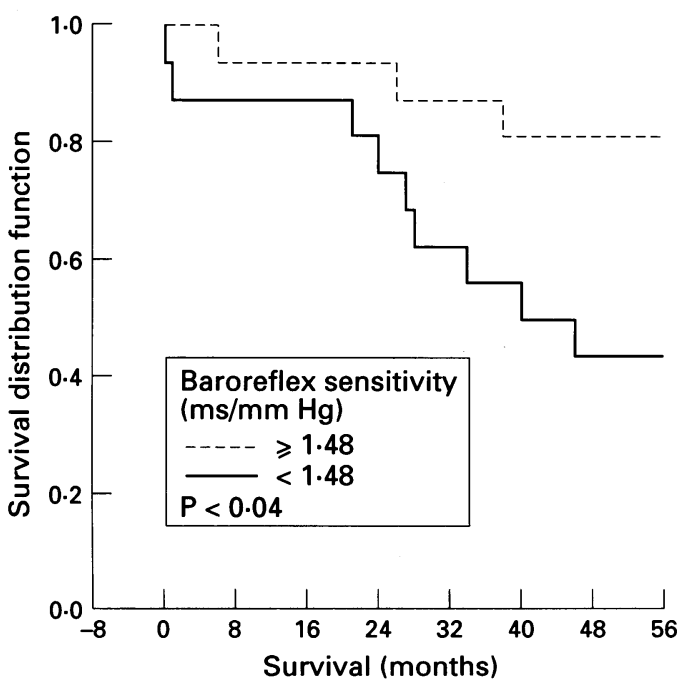

Figure 3 Survival in the 32 patients with mild to moderate heart failure when the patients with a maximal baroreflex sensitivity of the median value and above were compared with those with a baroreflex sensitivity below the median. The three patients receiving transplants were excluded from analysis. 
curves showed that three of 16 subjects (19\%) with a baroreflex sensitivity of $1.48 \mathrm{~ms} / \mathrm{mm}$ $\mathrm{Hg}$ or above had died, compared with nine of 16 patients $(56 \%)$ with a sensitivity below the median. When other variables thought to be related to prognosis were analysed by dividing the patients into two groups according to the median systolic blood pressure and systolic pulmonary artery pressure patients with a

Table 2 Comparison of patients who died of progressive heart failure $(n=6)$ or received transplant $(n=3)$ with those dying from sudden cardiac death. Values are means $(S D)$ unless stated otherwise

\begin{tabular}{|c|c|c|c|}
\hline & $\begin{array}{l}\text { Died of progressive } \\
\text { heart failure or } \\
\text { received transplant } \\
(n=9)\end{array}$ & $\begin{array}{l}\text { Sudden cardiac } \\
\text { death }(n=6)\end{array}$ & $\begin{array}{l}P \\
\text { value }\end{array}$ \\
\hline \multicolumn{4}{|l|}{ No of patients with: } \\
\hline Cardiomyopathy & 8 & 5 & NS \\
\hline Coronary artery disease & 1 & 1 & NS \\
\hline Age (years) & $54(5)$ & $57(12)$ & NS \\
\hline Height $(\mathrm{cm})$ & $174(3)$ & $175(3)$ & NS \\
\hline Weight $(\mathrm{kg})$ & $71(6)$ & $73(5)$ & NS \\
\hline Mean blood pressure $(\mathrm{mm} \mathrm{Hg})$ & $89(3)$ & $91(7)$ & 0.07 \\
\hline Heart rate (beats $/ \mathrm{min}$ ) & $88(5)$ & $99(8)$ & NS \\
\hline Cardiac index $\left(1 / \mathrm{min} / \mathrm{m}^{2}\right)$ & $3 \cdot 0(0 \cdot 2)$ & $2 \cdot 8(0 \cdot 3)$ & NS \\
\hline Stroke volume index $\left(\mathrm{ml} / \mathrm{m}^{2}\right)$ & $34(3)$ & $30(4)$ & NS \\
\hline Mean pulmonary artery pressure $(\mathrm{mm} \mathrm{Hg})$ & $35(2)$ & $35(5)$ & NS \\
\hline Mean right atrial pressure $(\mathrm{mm} \mathrm{Hg})$ & $9(2)$ & $9(2)$ & NS \\
\hline Systemic vascular resistance (dynes $\mathrm{s} / \mathrm{cm}^{5}$ ) & $1262(112)$ & $1243(47)$ & NS \\
\hline Plasma adrenaline $(\mathrm{pg} / \mathrm{ml})$ & $67(22)$ & $95(42)$ & NS \\
\hline Plasma noradrenaline $(\mathrm{pg} / \mathrm{ml})$ & $242(73)$ & $385(189)$ & NS \\
\hline Plasma renin activity (ng angioten $\sin \mathrm{I} / \mathrm{ml} / \mathrm{h}$ ) & $10 \cdot 6(5 \cdot 1)$ & $5 \cdot 2(1 \cdot 6)$ & NS \\
\hline Serum sodium $(\mathrm{mmol} / \mathrm{l})$ & $138(1)$ & $136(2)$ & NS \\
\hline Serum potassium $(\mathrm{mmol} / \mathrm{l})$ & $4 \cdot 2(0 \cdot 1)$ & $3.8(0 \cdot 3)$ & NS \\
\hline Serum creatinine $(\mathrm{mg} / 100 \mathrm{ml})$ & $1.4(0.2)$ & $1.5(0.1)$ & NS \\
\hline \multicolumn{4}{|l|}{ Baroreflex sensitivity $(\mathrm{ms} / \mathrm{mm} \mathrm{Hg})$ : } \\
\hline Maximal & $1 \cdot 3(0 \cdot 3)$ & $1.3(0.3)$ & NS \\
\hline Immediate & $1 \cdot 2(0.4)$ & $0.8(0 \cdot 3)$ & NS \\
\hline Survival time (months) & $26(4 \cdot 9)$ & $32(7 \cdot 9)$ & \\
\hline
\end{tabular}

Figure 4 Influence of systolic blood pressure and systolic pulmonary artery pressure on survival in the 32 patients with mild to moderate heart failure. The median of each variable was used to divide the patients into two groups, and the two survival curves were then compared. The three patients receiving transplants were excluded from analysis.
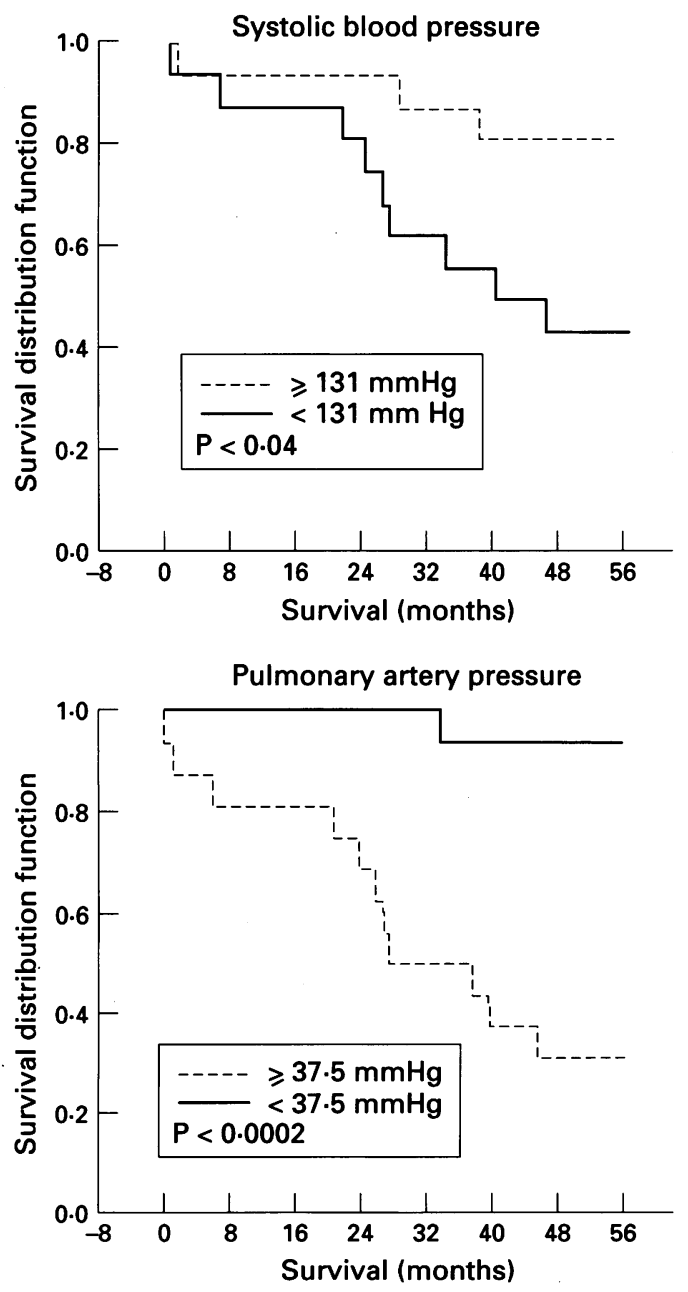

poor prognosis could be distinguished from those with a good prognosis (figure 4). Dividing the patients into two groups according to noradrenaline concentration and stroke volume did not allow such differentiation.

When the patients who received transplants were excluded five variables showed a univariate significant regression coefficient in terms of survival-namely, stroke volume index, the inverse of systolic blood pressure, pulmonary artery pressure, plasma noradrenaline concentration, and maximal baroreceptor sensitivity. The sequence of the variables considered in a stepwise procedure was derived from the significance level of the univariate analysis. Only two of these variables entered the multiple regression model $(P<0.001)$. These variables were systolic blood pressure and plasma noradrenaline concentration. The relation was defined by the Cox hazards model equation: $S(t ; z)=\left(S_{0}(t)\right)^{\exp \left(\beta^{\prime} z\right)}$, where $S(t ; z)=$ survival function at time $t$ and covariate values $\mathrm{z},\left(\mathrm{S}_{0}(\mathrm{t})\right)=$ baseline survival function corresponding to survival at $\mathrm{z}=0$, and $\beta^{\prime} z=-0.0364 \times$ systolic blood pressure $+0.0039 \times$ plasma noradrenaline concentration.

Similar results were obtained when the three patients who received transplants were included in the analysis.

\section{Discussion}

Two variables are closely associated with prognosis in patients with congestive heart failure-namely, left ventricular function and activation of the sympathetic nervous system. ${ }^{41819}$ Our data suggest that diminished baroreflex sensitivity representing low vagal tone is also a prognostic indicator in patients with congestive heart failure. Moreover, determining vagal tone may be useful not only in patients after myocardial infarction ${ }^{9} 1020$ but also in patients with symptomatic heart failure. To confirm the influence of vagal tone on prognosis, however, further studies are required in patients with heart failure. In a clinical setting this could be achieved by analysing heart rate variability, which is another way to measure vagal tone.

We used the baroreceptor reflex to determine the level of parasympathetic tone. We believe that this conclusion is justified because of earlier studies showing that the early reflex bradycardia elicited by neck suction is dependent only on reflex parasympathetic activation and is not influenced by the withdrawal of sympathetic tone. ${ }^{21}$ Thus, patients who show only a slight decrease in heart rate on neck suction show low parasympathetic activity. These patients have a poorer prognosis than patients with a brisk response.

Vagal tone may alter prognosis by its influence on malignant arrhythmias. This is supported by several studies. Dogs with myocardial infarction induced by having a ligature around one coronary artery were more likely than dogs whose vagal tone remained normal to develop ventricular fibrillation if their vagal tone was decreased. ${ }^{22}{ }^{23}$ Patients 
after myocardial infarction but without congestive heart failure had a significantly higher risk of sudden cardiac death when the vagal tone was low. ${ }^{924}$ We did not, however, find a greater risk of sudden death in our patients with diminished vagal tone, even though the immediate baroreceptor response tended to be lower in the subjects who died suddenly than in those who did not. Deterioration of left ventricular function is associated with a decrease in parasympathetic tone. ${ }^{612}{ }^{25}$ Vagal tone therefore identifies not only a subgroup at high-risk of sudden cardiac death but also a subgroup at high risk of pump failure. Both parameters are closely related to prognosis in heart failure; therefore indices of vagal tone are associated with both sudden cardiac death and terminal myocardial dysfunction, as we found in this study.

The sympathetic and parasympathetic nervous systems are regulated as an inverse servo mechanism: when sympathetic tone increases, parasympathetic tone decreases. Thus, sympathetic tone may have been greater in the patients who died than in those who had a better prognosis. The variability of plasma noradrenaline values precluded our showing a difference in the sympathetic tone of these two groups or a significantly different survival in the two groups on dividing the patients according to median noradrenaline concentrations. However, the multiple regression analysis we performed accepted only systolic blood pressure and plasma noradrenaline values. Since sympathetic and parasympathetic tone are highly inversely correlated, it is not surprising that the model accepted only one of these variables.

We did not determine left ventricular ejection fraction, which is a prognostic indicator in patients with congestive heart failure, ${ }^{23}$ but we found that other variables reflecting a poor left ventricular function were related to prognosis. When the median of systolic blood pressure or systolic pulmonary artery pressure was used to define two groups a significantly worse prognosis was found in patients with low systolic blood pressure or high pulmonary artery pressure. The multivariate approach, however, considers the study variables in their order of importance. We believe that systolic blood pressure reflected poor left ventricular function in our patients as blood pressure is determined in patients with depressed left ventricular function by the heart's ability to adequately supply the tissues at the required afterload. Schwartz et al reported similar findings, in that they were also able to show an independent contribution of systolic left ventricular pressure on prognosis.

Clinical studies have shown the importance of reduced sympathetic tone on the prognosis of congestive heart failure. ${ }^{56-28}$ In addition, clinical intervention trials have shown that by decreasing the activity of the renin-angiotensin system and the sympathetic nervous system, the prognosis of patients with congestive heart failure may be improved..$^{29-32}$ Angiotensin converting enzyme inhibitors would be expected to increase parasympa- thetic tone by two mechanisms. The lower angiotensin II concentrations could influence vagal tone centrally by acting at the area postrema, an area of the brain where the blood-brain barrier is particularly sensitive to the influences of circulating concentrations of angiotensin II. ${ }^{33}$ Furthermore, global haemodynamic improvements evoked by angiotensin converting enzyme inhibitors would be expected to improve parasympathetic tone. Thus, parasympathetic tone may extend beyond heart rate responses. For instance, in patients with severe mitral insufficiency an increase in vagal tone was associated with improved haemodynamics. ${ }^{34}$ Finally, we recently showed an increase in cardiac vagal activity after angiotensin converting enzyme inhibition. ${ }^{12}$ This was confirmed by Binkley $e t$ $a l$, who found an augmentation of vagal tone after treatment with converting enzyme inhibitors in patients with heart failure. The effects of converting enzyme inhibitors may be partly mediated in this way. For instance, studies in humans suggest that the antiarrhythmic action of converting enzyme inhibitors may be based on the suppression of foci triggered by ischaemia ${ }^{2223}$ or the suppression of ventricular tachycardia. ${ }^{35}$ This conclusion is supported by the results of the second vasodilator heart failure trial, in which the incidence of sudden death was reduced with enalapril compared with hydralazineisosorbide dinitrate in patients with mild heart failure. ${ }^{27} 36$

1 Likoff MJ, Chandler SL, Kay HR. Clinical determinants of mortality in chronic congestive heart failure secondary to idiopathic dilated or to ischemic cardiomyopathy. Am f Cardiol 1987;59:634-8.

2 Cohn JN, Rector TS. Prognosis of congestive heart failure and predictors of mortality. Am $\mathcal{f}$ Cardiol 1988;62: 25-30A.

3 Schwarz F, Mall G, Zebe H, et al. Determinants of survival in patients with congestive cardiomyopathy: quantitative in patients with congestive cardiomyopathy: quantitative
morphologic findings and left ventricular hemomorphologic findings and left

4 Cohn JN, Levine TB, Olivari MT, et al. Plasma norepinephrine as a guide to prognosis in patients with chronic congestive heart failure. N Engl F Med 1984;311:819-23.

5 Francis GS, Cohn JN, Johnson G, Rector TS, Goldman S, Simon A. Plasma norepinephrine, plasma renin activity, and congestive heart failure. Relations to survival and the effects of therapy in V-HeFT II. The V-HeFT VA Cooperative Studies Group. Circulation 1993;87: VI40-8

6 Eckberg DL, Drabinsky M, Braunwald E. Defective cardiac parasympathetic control in patients with heart disease. N Engl ๆ Med 1971;285:877-83.

7 Binkley PF, Nunziata E, Haas GJ, Nelson SD, Cody RJ Parasympathetic withdrawal is an integral component of Parasympathetic withdrawal is an integral component of autonomic imbalance in congestive heart failure: demonstration in human subjects and verification in a paced canine model of

8 Mancia G, Ferrari A, Gregorini L, et al. Control of blood pressure by carotid sinus baroreceptors in human beings. pressure by carotid sinus barorece

9 La Rovere MT, Specchia G, Mortara A, Schwartz PJ. Baroreflex sensitivity, clinical correlates, and cardiovascular mortality among patients with a first myocardial infarction. A prospective study. Circulation 1988;78: 816-24.

$10 \mathrm{La}$ Rovere MT, Mortara A, Specchia G, Schwartz PJ. Myocardial infarction and baroreflex sensitivity. Clinical studies. G Ital Cardiol 1992;22:639-45.

11 Ludbrook J, Mancia G, Ferrari A, Zanchetti A. The variable-pressure neck-chamber method for studying the carotid baroreflex in man. Clin Sci 1977;53:165-71.

12 Osterziel KJ, Dietz R, Schmid W, Mikulaschek K, Manthey J, Kübler W. ACE-inhibition improves vagal reactivity in patients with heart failure. Am Heart f 1990; 120:1120-9.

13 Ebert TJ. Captopril potentiates chronotropic baroreflex responses to carotid stimuli in humans. Hypertension 1985;7:602-6. 
14 Da Prada M, Zürcher G, Hoffmann-La Roche. Simultaneous radioenzymatic determination of plasma and tissue adrenaline, noradrenaline and dopamine within the femtomole range. Life Sci 1976;19:1161-74.

15 Hackenthal E, Hackenthal $R$, Hilgenfeldt U. Isorenin pseudorenin, cathepsin $\mathrm{D}$ and renin $\mathrm{A}$ comparative pseudorenin, cathepsin $\mathrm{D}$ and renin A comparative enzymatic study of angiotensin-formin

16 Schuster VL, Seldin DW. Renal clearance. In: Seldin DW, Giebisch G, eds. The kidney: physiology and pathoGiebisch G, eds. The kidney: physiology

17 Hinkle LE, Thaler HT. Clinical classification of cardiac death. Circulation 1982;65:457-64

18 Lee WH, Packer M. Prognostic importance of serum sodium concentration and its modification by converting-enzyme inhibition in patients with severe chronic heart failure. Circulation 1986;73:257-67.

19 Swedberg K, Eneroth P, Kjekshus J, Wilhelmsen L for the CONSENSUS Trial Study Group. Hormones regulating cardiovascular function in patients with severe hear failure and their relation to mortality. Circulation 1990; 82:1730-6.

20 Sneddon JF, Bashir Y, Ward DE. Vagal stimulation after myocardial infarction: accentuating the positive. $f \mathrm{Am}$ Coll Cardiol 1993;22:1335-7.

21 Mancia G, Mark AL. Arterial baroreflexes in humans. In Shepherd JT, Abboud FM, eds. Handbook of physiology-the cardiovascular system III. Baltimore: Waverly, ology-the cardio

22 Billman GE, Schwartz PJ, Stone HL. Baroreceptor reflex control of heart rate: a predictor of sudden cardiac death. Circulation 1982;66:874-80.

23 Schwartz PJ, Vanoli E, Stramba-Badiale M, De Ferrar GM, Billman GE, Foreman RD. Autonomic mechanisms and sudden death: new insights from the analysis of baroreceptor reflexes in conscious dogs with and withou a myocardial infarction. Circulation 1988;78:969-73.

24 Kleiger RE, Miller JP, Bigger JT, Moss AJ, Multicente Post-Infarction Research Group. Decreased heart rate variability and its association with increased mortality after acute myocardial infarction. Am $\mathcal{f}$ Cardiol 1987; 59:256-62.

25 Binkley PF, Haas GJ, Starling CR, et al. Sustained augmentation of parasympathetic tone with angiotensin-converting enzyme inhibition in patients with congestive heart failure. Am $\mathcal{f}$ Cardiol 1993;21:655-61. 26 Cohn JN, Archibald DG, Ziesche S, et al. Effect of vasodilator therapy on mortality in chronic congestive heart failure. N Engl f Med 1986;314:1547-52.

27 Cohn JN, Johnson G, Ziesche S, et al. A comparison of enalapril with hydralazine-isosorbide dinitrate in the treatment of chronic congestive heart failure. $N$ Engl $\mathcal{F}$ treatment of chronic cone $1991 ; 325: 303-10$.

28 Swedberg K, Eneroth P, Kjekshus J, Snapinn S. Effects of enalapril and neuroendocrine activation on prognosis in severe congestive heart failure (follow-up of the CONSENSUS trial). Am f Cardiol 1990;66:40-5D.

29 CONSENSUS Trial Study Group. Effects of enalapril on mortality in severe congestive heart failure. $N \mathrm{Engl} F \mathrm{Med}$ 1987;316:1429-35.

30 SOLVD Investigators. Studies of left ventricular dysfunction (SOLVD)-rationale, design and methods: two trials that evaluate the effect of enalapril in patients with reduced ejection fraction. Am $\mathcal{f}$ Cardiol 1990;66: 315-22.

31 SOLVD Investigators. Effect of enalapril on mortality and the development of heart failure in asymptomatic patients with reduced left ventricular ejection fractions. N Engl F Med 1992;327:685-91.

32 Brodde O-E. Physiology and pharmacology of cardiovascular catecholamine receptors: implications for treatcular catecholamine receptors: implications for treat-
ment of chronic heart failure. Am Heart $f$ 1990;120: 1565-72.

33 Joy MD, Lowe RD. Evidence that the area postrema mediates the central cardiovascular response to angiotensin ates the central cardiovascular

34 Wisenbaugh T, Essop R, Sareli P. Short-term vasodilator effect of captopril in patients with severe mitral regurgitation is parasympathetically mediated. Circulation 1993; 84:2049-53.

35 Fletcher RD, Cintron GB, Johnson G, Orndorff J, Carson $P$, Cohn JN. Enalapril decreases prevalence of ventricular tachycardia in patients with chronic congestive heart failure. The V-HeFT II VA Cooperative Studies Group. Circulation 1993;87:VI49-55.

36 Goldman S, Johnson G, Cohn JN, Cintron G, Smith R, Francis G. Mechanism of death in heart failure. The vasodilator-heart failure trials. The V-HeFT VA Cooperative Studies Group. Circulation 1993;87: V124-31. 